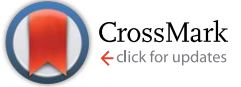

Cite this: Chem. Sci., 2015, 6, 4525

Received 15th May 2015

Accepted 6th June 2015

DOI: $10.1039 / c 5 s c 01772 f$

www.rsc.org/chemicalscience

\section{Ligand-enabled Ir-catalyzed intermolecular diastereoselective and enantioselective allylic alkylation of 3-substituted indoles $\uparrow$}

\author{
Xiao Zhang, ${ }^{a}$ Wen-Bo Liu, ${ }^{a}$ Hang-Fei Tu${ }^{a}$ and Shu-Li You*ab \\ An Ir-catalyzed asymmetric allylic alkylation of 3-substituted indoles is reported. The reaction provides \\ indoline products containing multiple contiguous stereocenters with high site-, regio-, diastereo- and \\ enantioselectivities in one step from a wide range of readily available starting materials. The key to this \\ method is the high level of diastereocontrol enabled by an iridium catalyst derived from a $\mathrm{N}$-aryl \\ phosphoramidite ligand (Me-THQphos, 1c).
}

Polycyclic indoline skeletons are present in a variety of alkaloid natural products with diverse biological activities, and many of them bear multiple contiguous stereogenic centers. ${ }^{1}$ A large number of notable methods have been devised toward the synthesis of this privileged structure in the past several decades, ${ }^{2}$ including a chiral pool strategy from tryptophan derivatives, ${ }^{3}$ stereoselective functionalization of oxindoles followed by cyclizations, ${ }^{4}$ and recently, catalytic enantioselective tandem C3-functionalization/cyclization reactions of 3 -substituted indoles, ${ }^{5}$ and others. ${ }^{6}$

However, the existing methods are mainly limited to the construction of endocyclic vicinal stereocenters (C2 and C3) of indolines. Given the complexity and importance of indoline alkaloids with an additional tertiary stereocenter $\left(\mathrm{C}^{\prime}\right)$ adjacent to the C3 quaternary center (Fig. 1), the development of efficient methods to install these three contiguous stereocenters in one operation is highly appealing but remains a formidable challenge in organic synthesis. ${ }^{7}$ We envisioned that iridium-catalyzed reactions of 3 -substituted indoles with allylic carbonates have the potential to create these stereogenic arrangements in a single step.

To achieve this, the reaction must show high levels of site selectivity for indoles with regard to N1, C3 and the side chain nucleophiles $(\mathrm{X}){ }^{8}$ regioselectivity toward branched or linear $\left(\mathrm{C}^{\prime}\right.$ vs. $\left.\mathrm{C}^{\prime}\right)$, and enantioselectivity and diastereoselectivity with respect to the new $\mathrm{C} 3-\mathrm{C} 3{ }^{\prime}$ bond (Scheme 1). Despite the rapid growth of Ir-catalyzed allylic alkylations, ${ }^{9}$ control of the regioand enantioselectivity of the reaction using sterically hindered

${ }^{a}$ State Key Laboratory of Organometallic Chemistry, Shanghai Institute of Organic Chemistry, Chinese Academy of Sciences, 345 Lingling Lu, Shanghai 200032, China. E-mail: slyou@sioc.ac.cn

${ }^{b}$ Collaborative Innovation Center of Chemical Science and Engineering, Tianjin, China $\dagger$ Electronic supplementary information (ESI) available. CCDC 1060973. For ESI and crystallographic data in CIF or other electronic format see DOI: $10.1039 / \mathrm{c} 5 \mathrm{sc} 01772 \mathrm{f}$ nucleophiles has proven to be problematic. Two recently reported examples have provided direct access to 3-substituted pyrroloindolines in one step by iridium-catalysis, ${ }^{10}$ however, these reactions either afford only linear allylated products or lack enantioselectivity. In particular, the diastereocontrol of prochiral nucleophiles represents a significant challenge. To date, only a handful of examples of the intermolecular diastereoselective allylic alkylation of prochiral nucleophiles have been established, ${ }^{11-14}$ through the use of iridium catalysis combined with a judicious choice of additives, ${ }^{12,13}$ or synergistic iridium/amine dual catalysis. ${ }^{14}$ Moreover, the nucleophiles investigated in these accounts were limited to glycine derivatives, azlactones, and enolates. Our group has a strong focus on and interest in addressing the facial selectivity of prochiral nucleophiles by engineering new ligand structures. We have

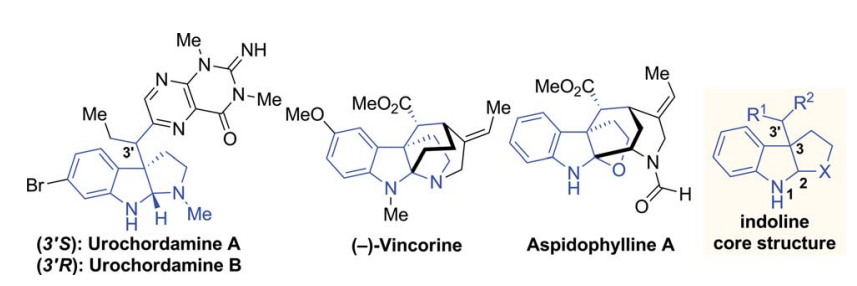

Fig. 1 Representative indoline natural products.

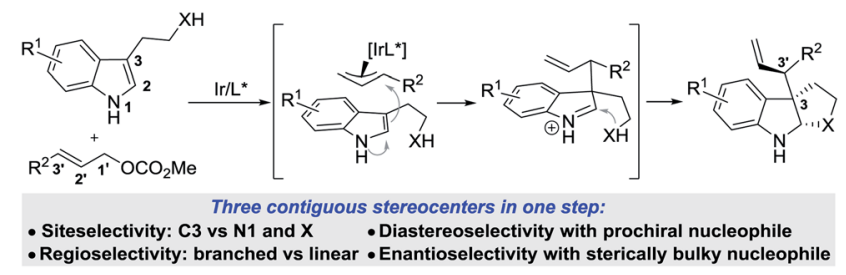

Scheme 1 Ir-catalyzed allylic alkylation of 3-substituted indoles. 
developed an iridacycle complex derived from 2-methyl-1,2,3,4tetrahydroquinoline phosphoramidite (Me-THQPhos, 1c) and $[\operatorname{Ir}(\mathrm{COD}) \mathrm{Cl}]_{2},{ }^{15}$ which was found to be an efficient catalyst enabling diastereocontrol in both intra- and intermolecular Ircatalyzed allylic allylations, by our group ${ }^{16}$ and others. ${ }^{13}$ We recently found that the use of ligand $1 \mathrm{c}$ is crucial to the outcome with regard to regio-, diastereo-, and enantioselectivities in the synthesis of indolines (Scheme 1). Herein, we wish to report our preliminary results on this unprecedented Ir-catalyzed tandem allylic alkylation/cyclization reaction.

Since we hypothesized that the catalysts may play a key role in the stereoselectivity, our studies were initiated by investigating phosphoramidite ligands with tryptophol 2a and cinnamyl carbonate $\mathbf{3 a}$ as model substrates (Table 1). Exposure of the substrates to the catalyst derived from the Feringa ligand 1a (ref. 17a) or the Alexakis ligand $\mathbf{1 b}$ (ref. 17b) and 1 equiv. of $\mathrm{Cs}_{2} \mathrm{CO}_{3}$ in THF provided furoindoline 4 aa in good yield as a

Table 1 Optimization of the reaction conditions ${ }^{a}$
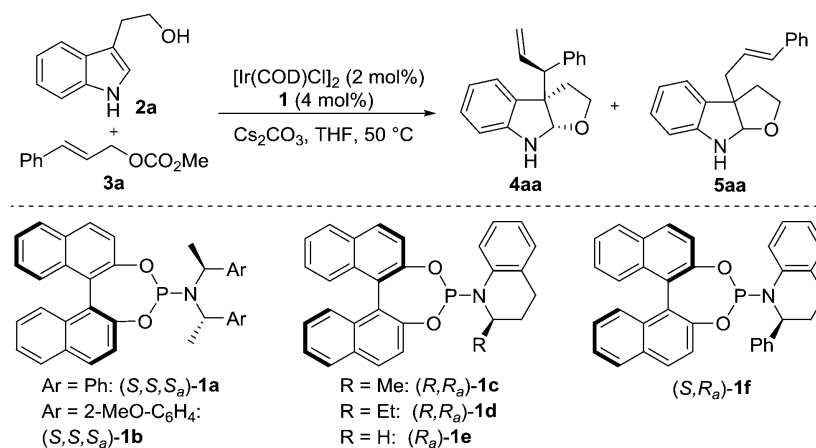
$\mathrm{R}=\mathrm{Et}:\left(R, R_{a}\right)-1 \mathrm{~d}$ $\mathrm{R}=\mathrm{H}:\left(R_{\mathrm{a}}\right)-1 \mathrm{e}$

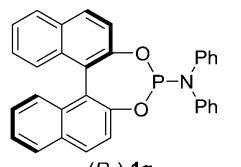

$\left(R_{a}\right)-1 g$

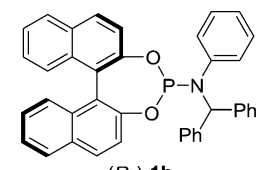

$\left(R_{a}\right)-1 \mathrm{~h}$
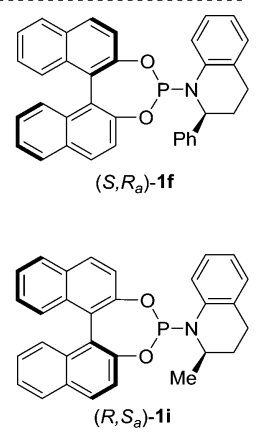

\begin{tabular}{llrlll}
\hline Entry & Ligand (1) & $t(\mathrm{~h})$ & $\operatorname{dr}(\mathbf{4 a a})^{b}$ & ${\text { Yield }(\mathbf{4 a a})^{c}(\%)}$ ee $^{d}(\%)$ \\
\hline 1 & 1a & 12 & $2 / 1$ & 50 & 86 \\
2 & 1b & 3 & $3 / 1$ & 76 & 90 \\
3 & 1c & 5 & $5 / 1$ & 84 & 87 \\
4 & 1d & 9 & $5 / 1$ & 84 & 86 \\
5 & $\mathbf{1 e}$ & 24 & $10 / 1$ & 28 & 90 \\
6 & $\mathbf{1 f}$ & 3 & $1 / 1$ & 72 & 90 \\
7 & $\mathbf{1 g}$ & 24 & $9 / 1$ & 32 & 92 \\
$8^{e}$ & $\mathbf{1 h}$ & 3 & $2 / 1$ & 86 & 90 \\
9 & $\mathbf{1 i}$ & 24 & $9 / 1$ & 36 & -90 \\
$10^{f}$ & $\mathbf{1 c}$ & 6 & $8 / 1$ & 82 & 90 \\
$11^{f, g}$ & $\mathbf{1 c}$ & 12 & $15 / 1$ & 70 & 95 \\
$12^{f, g, h}$ & $\mathbf{1 c}$ & 12 & $>20 / 1$ & 82 & 95
\end{tabular}

${ }^{a}$ The reaction was performed with $0.2 \mathrm{mmol}$ of $2 \mathrm{a}, 1.5$ equiv. of $3 \mathrm{a}$ and 1 equiv. of $\mathrm{Cs}_{2} \mathrm{CO}_{3}$. Ir-catalyst was prepared in situ with $n-\mathrm{PrNH}_{2}$. ${ }^{b}$ Determined by ${ }^{1} \mathrm{H}$ NMR of the crude reaction mixture. Unless otherwise noted, $\mathbf{4 a a} / \mathbf{5 a a}=>95 / 5 .{ }^{c}$ Isolated yield. ${ }^{d}$ ee of $\mathbf{4 a a}$ was determined using HPLC analysis (Chiralpak IC). ${ }^{e}$ 4aa/5aa $=90 / 10 .{ }^{f} 1$ equiv. of $\mathrm{Et}_{3} \mathrm{~N}$ was used with $2 \mathbf{a} / 3 \mathbf{a}=2 / 1{ }^{g}$ At rt. ${ }^{h}$ Ir-catalyst was prepared in situ with TBD. mixture of diastereomers (2/1-3/1 dr, entries 1 and 2). We envisioned that the low diastereoselectivity may originate from the weak interaction between the sterically encumbered cyclometalated Ir-allyl complex ${ }^{18}$ and the bulky nucleophile. Efforts to improve the diastereoselectivity were made by conducting a survey of several $N$-aryl substituted ligands (entries 3-9). The superior diastereocontrol observed in the cases of the less bulky ligands (i.e., 1c-e, 1g and 1i) compared to that of the more bulky ligands (i.e., 1a, $\mathbf{1 b}, \mathbf{1 f}$ and $\mathbf{1 h}$ ) again suggested the importance of the ligand structure in the facial discrimination of indoles. However, if the ligand's steric bulk was too small (i.e., 1e and 1g), the reactivity tended to be lower (28-32\% yields, entries 5 and 7). To our delight, ligand 1c finally emerged as the optimal one for both yield and diastereoselectivity (entry 3 ).

Further optimization was conducted by screening various bases, temperatures, substrate ratios, and the activators used in the catalyst in situ preparation (entries 10-12). ${ }^{19-21}$ These results revealed that the use of excess nucleophile and the combination of $\mathrm{Et}_{3} \mathrm{~N}$ and catalyst generated in situ by TBD could provide $4 \mathrm{aa}$ in $82 \%$ yield with $>20 / 1 \mathrm{dr}$ and $95 \%$ ee at room temperature (entry 12).

With the optimized reaction conditions in hand, we next studied the scope of different allylic carbonates amenable to the chemistry (Scheme 2). Carbonates containing either electrondonating (4-MeO, 4-Me, 3-MeO and 3-Me) or electron-

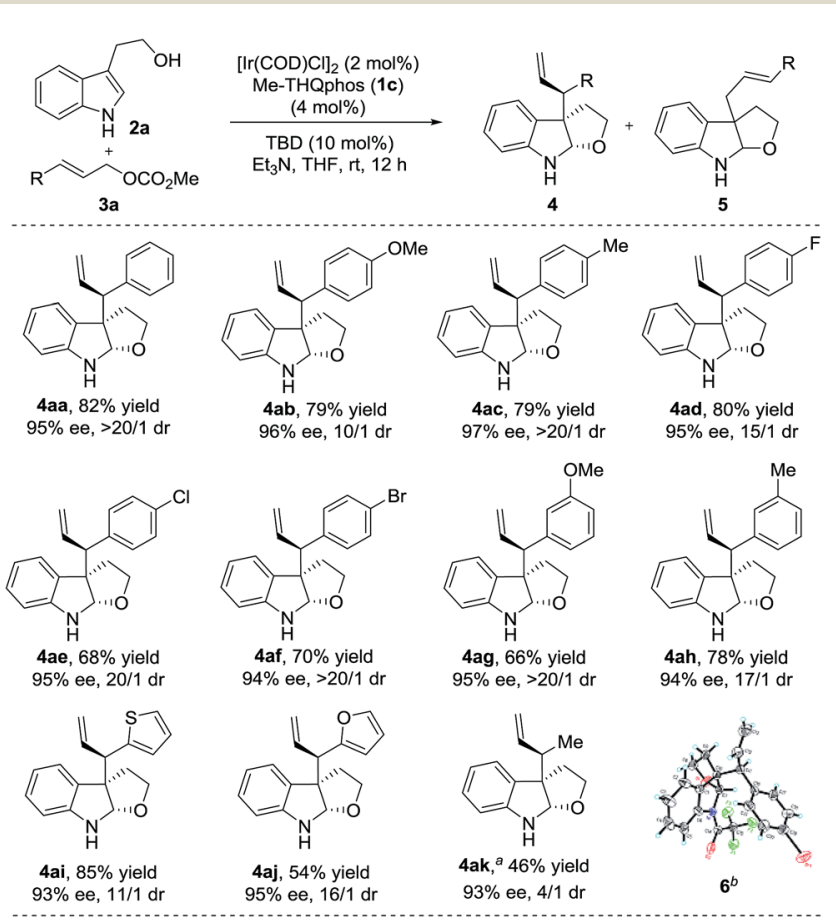

Scheme 2 Substrate scope of electrophiles. The reactions were performed under the conditions of Table 1, entry 12. The yields of isolated product 4 are shown. The $d r$ was determined using ${ }^{1} \mathrm{H}$ NMR of the crude reaction mixture and the ee was determined using chiral HPLC. Unless otherwise noted, $4 / 5=>95 / 5$. ${ }^{a}$ Reaction time was $18 \mathrm{~h}$ and $4 / 5=85 / 15{ }^{b}$ The absolute configuration of 4 af was determined using $X$-ray analysis of its trifluoroacetyl-protected derivative $6 .{ }^{19}$ The absolute configuration of all other products was determined by analogy. 
withdrawing (4-F, 4-Cl and 4-Br) substituents on the phenyl ring were well tolerated and delivered the corresponding products efficiently (4aa-4ah, 66-82\% yields, 10/1->20/1 dr and 94-97\% ee).

In addition, heteroaryl allylic carbonates, such as 2-thienyl and 2-furanyl, were also compatible with this transformation (4ai and 4aj, 11/1-16/1 dr and 93-95\% ee). Gratifyingly, the reaction with methyl crotyl carbonate led to the desired product 4ak in excellent enantioselectivity (93\% ee), albeit with a slightly lower $\mathrm{dr}$ than for aromatic substituted carbonates. To the best of our knowledge, this is the first example of the application of an aliphatic allylic carbonate in the Ir-catalyzed allylic alkylation of prochiral nucleophiles which can achieve good diastereoand enantioselectivities.

Subsequently, we set out to investigate the scope of nucleophiles. A variety of indoles with diverse substituents were examined and the results are summarized in Scheme $3 .^{22}$ Different substituents (4- $\mathrm{Me}, 5-\mathrm{MeO}, 5-\mathrm{Cl}, 5-\mathrm{Br}$ and $6-\mathrm{Cl}$ ) on the tryptophols were well tolerated in all cases delivering the desired furoindoline products smoothly (4ba-4fa, 50-83\% yields, 10/1->20/1 dr and 91-97\% ee). Pyranoindoline 4ga was also obtained in good yield and selectivities. In addition, employing tryptamines with varied protecting groups $\left(\mathrm{CO}_{2} \mathrm{Me}\right.$,
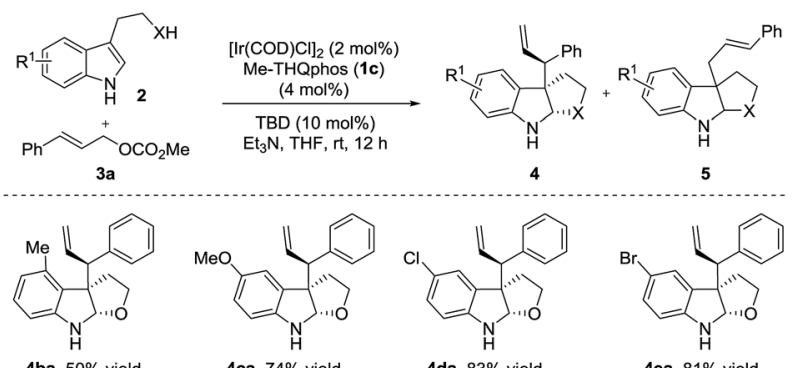

$97 \%, 50 \%$ yield
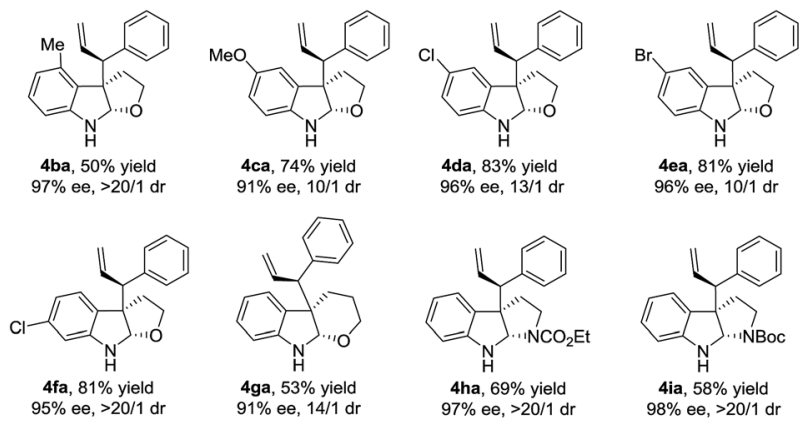

$91 \%$ ee, $10 / 1 \mathrm{dr}$ $96 \%$ ee, $13 / 1 \mathrm{dr}$ $96 \%$ ee, $10 / 1 \mathrm{dr}$
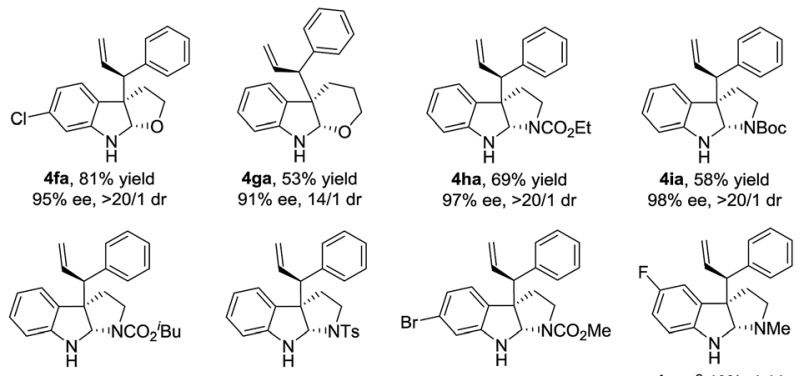

$4 \mathrm{ja}, 58 \%$ yield $96 \%$ ee, $14 / 1 \mathrm{dr}$
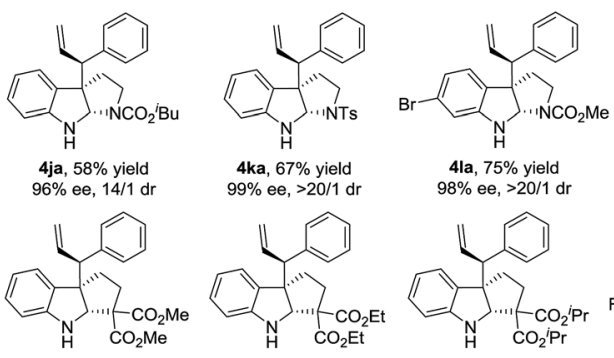

4ka, $67 \%$ yield
$99 \%$ ee, $>20 / 1 \mathrm{dr}$

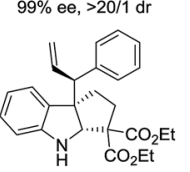
$98 \%$ ee, >20/1 dr

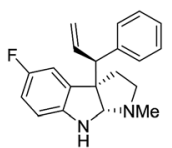

$4 \mathrm{ma},{ }^{a} 40 \%$ yield $99 \%$ ee, > $20 / 1 \mathrm{dr}$
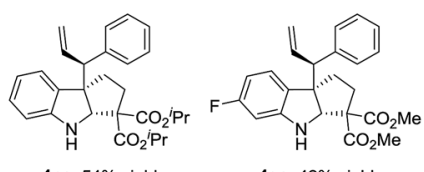

4 na, $48 \%$ yield

$40 a, 67 \%$ yield $98 \%$ ee, $19 / 1 \mathrm{dr}$

$4 \mathrm{pa}, 54 \%$ yield

$4 q a, 42 \%$ yield $99 \%$ ee, $>20 / 1 \mathrm{dr}$

Scheme 3 Substrate scope of nucleophiles. The reactions were performed under the conditions of Table 1, entry 12. The yields of isolated product 4 are shown. The dr was determined using ${ }^{1} \mathrm{H}$ NMR of the crude reaction mixture and the ee was determined using chiral HPLC. Unless otherwise noted, $4 / 5=>95 / 5 .{ }^{a}$ 4ma was obtained through an allylic alkylation of methyl (2-(5-fluoro- $1 \mathrm{H}$-indol-3-yl)ethyl)carbamate and a subsequent reduction using $\mathrm{LiAlH}_{4} \cdot{ }^{19}$
$\mathrm{CO}_{2} \mathrm{Et}$, Boc, $\mathrm{CO}_{2}{ }^{i} \mathrm{Bu}$ and $\mathrm{Ts}$ ) on the nitrogen of the linkage and halogen substituents on the aromatic ring all resulted in the corresponding products (58-75\% yields, 4ha-4la). Upon treatment with $\mathrm{LiAlH}_{4}$, the $\mathrm{N}-\mathrm{Me}$ substituted compound 4ma was obtained in $40 \%$ yield in two steps. ${ }^{19}$ The excellent diastereoand enantioselectivities (14/1->20/1 dr and 96-99\% ee) of these particularly valuable pyrroloindolines demonstrate the potential of this method in the synthesis of complex alkaloid natural products. We also found that indoles with carbon nucleophile side chains were well compatible and proceeded to give cyclopentaneindoline products 4 na-4qa under the same conditions in moderate yields (42-67\%) with excellent stereoselectivities (19/1->20/1 dr and 97-99\% ee). ${ }^{23}$

Remarkably, the reaction also tolerates chiral nucleophiles such as tryptophan derivatives. Subjecting the L-tryptophan derivative (-)-2r to the reaction conditions afforded the corresponding product cis-4ra with a good $\mathrm{dr}$ and in a moderate yield (Scheme 4a). Similarly, employment of the D-tryptophan derivative (+)-2r led to indoline trans-4ra in a slightly better yield, albeit as a 3.5/1 mixture of diastereoisomers (Scheme $4 \mathrm{~b}$ ). Both of the major isomers of the above reactions shared the identical stereochemical configuration at the three newly formed centers (C2, C3 and C3'), suggesting that ligand-enabled catalyst control is responsible for establishing the absolute stereochemistry at these three centers, ${ }^{15 b}$ while a pre-existing chiral center in the substrate could also bias the stereochemical outcomes albeit to a lesser extent.

In order to demonstrate the utility of this method, a gramscale reaction was carried out, achieving good yield and

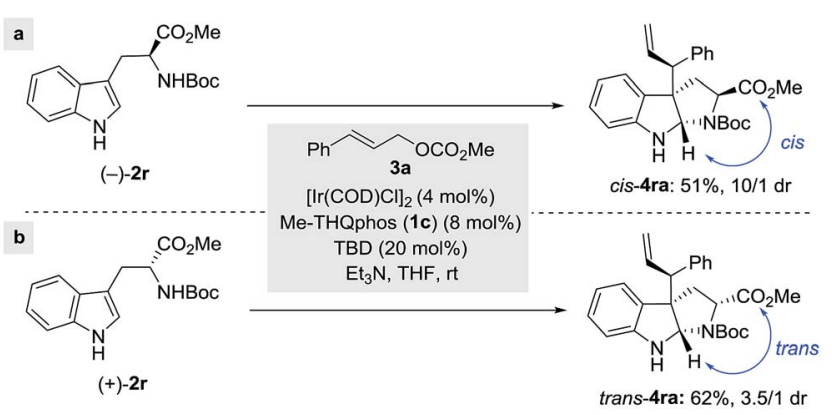

Scheme 4 Allylic alkylation of $N$-Boc protected tryptophan methyl ester.

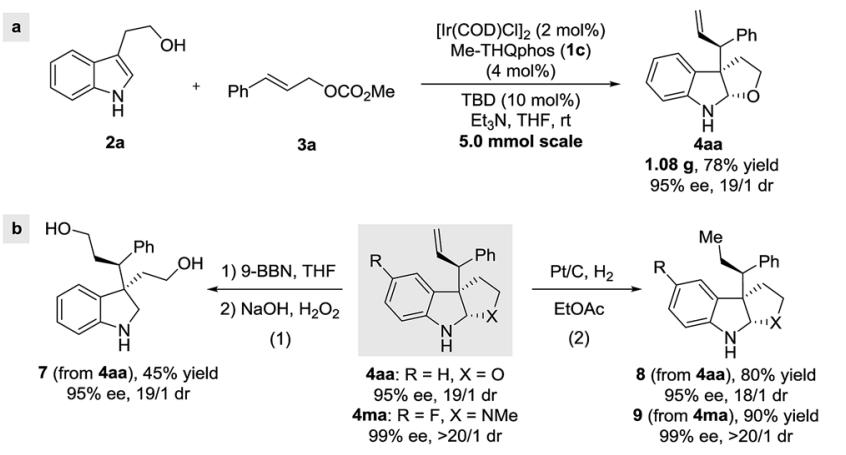

Scheme 5 Gram-scale synthesis and product transformations. 
selectivities (Scheme 5a). Furthermore, hydroboration/oxidation of the terminal olefin in 4aa was achieved without a loss of enantiomeric purity (eqn (1), Scheme 5b). Finally, Pt/C-catalyzed hydrogenation afforded the corresponding furoindoline $\mathbf{8}$ and pyrroloindoline 9 (eqn (2), Scheme 5b), with excellent diastereoselectivities and enantioselectivities, showcasing the synthetic potential of this protocol.

\section{Conclusions}

In conclusion, we have developed an iridium-catalyzed intermolecular allylic alkylation reaction of 3-substituted indoles with high site-, regio-, diastereo-, and enantioselectivities. The transformation, in which three stereocenters are formed in a single step, provides efficient access to structurally complex polycyclic indolines from simple starting materials. We also demonstrate that stereoselectivity is mainly controlled by the catalyst when tryptophan derivatives are used. Critical to this strategy is the employment of the Me-THQPhos (1c) ligand. Further mechanistic studies and the application of this method in natural product synthesis is ongoing in our laboratory.

\section{Acknowledgements}

We thank the National Basic Research Program of China (973 Program 2015CB856600), the National Natural Science Foundation of China $(21332009,21421091)$, and the Chinese Academy of Sciences for generous financial support.

\section{Notes and references}

1 (a) U. Anthoni, C. Christophersen and P. H. Nielsen, in Alkaloids: Chemical and Biological Perspectives, ed. S. W. Pelletier, Pergamon, Oxford, 1999, pp. 163-236; (b) S. Tsukamoto, H. Hirota, H. Kato and N. Fusetani, Tetrahedron Lett., 1993, 34, 4819; (c) A. Steven and L. E. Overman, Angew. Chem., Int. Ed., 2007, 46, 5488; (d) M. A. Schmidt and M. Movassaghi, Synlett, 2008, 313.

2 For reviews: (a) C.-X. Zhuo, W. Zhang and S.-L. You, Angew. Chem., Int. Ed., 2012, 51, 12662; (b) L. M. Repka and S. E. Reisman, J. Org. Chem., 2013, 78, 12314.

3 (a) S. P. Marsden, K. M. Depew and S. J. Danishefsky, J. Am. Chem. Soc., 1994, 116, 11143; (b) D. Crich and X. Huang, J. Org. Chem., 1999, 64, 7218; (c) M. Kawahara, A. Nishida and M. Nakagawa, Org. Lett., 2000, 2, 675; (d) L. Shen, M. Zhang, Y. Wu and Y. Qin, Angew. Chem., Int. Ed., 2008, 47, 3618; (e) J. Kim and M. Movassaghi, J. Am. Chem. Soc., 2011, 133, 14940; $(f)$ N. Boyer and M. Movassaghi, Chem. Sci., 2012, 3, 1798; (g) M. E. Kieffer, K. V. Chuang and S. E. Reisman, J. Am. Chem. Soc., 2013, 135, 5557.

4 (a) A. Huang, J. J. Kodanko and L. E. Overman, J. Am. Chem. Soc., 2004, 126, 14043; (b) B. M. Trost and Y. Zhang, J. Am. Chem. Soc., 2006, 128, 4590; (c) S. Ma, X. Han, S. Krishnan, S. C. Virgil and B. M. Stoltz, Angew. Chem., Int. Ed., 2009, 48, 8037; (d) H. Zhang, L. Hong, H. Kang and R. Wang, J. Am. Chem. Soc., 2013, 135, 14098; (e) B. M. Trost, M. Osipov, S. Krüger and Y. Zhang, Chem. Sci., 2015, 6, 349.
5 (a) J. F. Austin, S.-G. Kim, C. J. Sinz, W.-J. Xiao and D. W. C. MacMillan, Proc. Natl. Acad. Sci. U. S. A., 2004, 101, 5482; (b) B. M. Trost and J. Quancard, J. Am. Chem. Soc., 2006, 128, 6314; (c) L. M. Repka, J. Ni and S. E. Reisman, J. Am. Chem. Soc., 2010, 132, 14418; (d) S. Zhu and D. W. C. MacMillan, J. Am. Chem. Soc., 2012, 134, 10815; (e) G. Cera, M. Chiarucci, A. Mazzanti, M. Mancinelli and M. Bandini, Org. Lett., 2012, 14, 1350; (f) X. Zhang, L. Han and S.-L. You, Chem. Sci., 2014, 5, 1059; (g) H. Wang and S. E. Reisman, Angew. Chem., Int. Ed., 2014, 53, 6206; (h) W. Shao, H. Li, C. Liu, C.-J. Liu and S.-L. You, Angew. Chem., Int. Ed., 2015, 54, 7684.

6 Selected examples: (a) L. E. Overman, D. V. Paone and B. A. Stearns, J. Am. Chem. Soc., 1999, 121, 7702; (b) K. Tanaka, T. Taniguchi and K. Ogasawara, Tetrahedron Lett., 2001, 42, 1049; (c) A. Pinto, Y. Jia, L. Neuville and J. Zhu, Chem.-Eur. J., 2007, 13, 961; (d) A. B. Dounay, P. G. Humphreys, L. E. Overman and A. D. Wrobleski, J. Am. Chem. Soc., 2008, 130, 5368; (e) J. E. Spangler and H. M. L. Davies, J. Am. Chem. Soc., 2013, 135, 6802.

7 For an organocatalytic construction of pyrroloindolines bearing three contiguous stereocenters, see ref. $5 \mathrm{a}$.

8 For Ir-catalyzed C3 and N1 allylic alkylation of indoles, see: (a) W.-B. Liu, H. He, L.-X. Dai and S.-L. You, Org. Lett., 2008, 10, 1815; (b) L. M. Stanley and J. F. Hartwig, Angew. Chem., Int. Ed., 2009, 48, 7841 and ref. 5f. For selected examples on Pd-catalyzed asymmetric allylic alkylation of 3-substituted indoles, see: (c) M. Bandini, A. Melloni, F. Piccinelli, R. Sinisi, S. Tommasi and A. Umani-Ronchi, J. Am. Chem. Soc., 2006, 128, 1424; (d) Y. Zhu and V. H. Rawal, J. Am. Chem. Soc., 2012, 134, 111; (e) Y. Liu and H. Du, Org. Lett., 2013, 15, 740, and ref. 5 b.

9 Selected reviews: (a) G. Helmchen, A. Dahnz, P. Dübon, M. Schelwies and R. Weihofen, Chem. Commun., 2007, 675; (b) G. Helmchen, in Iridium Complexes in Organic Synthesis, ed. L. A. Oro and C. Claver, Wiley-VCH, Weinheim, 2009, pp. 211-250; (c) J. F. Hartwig and M. J. Pouy, Top. Organomet. Chem., 2011, 34, 169; (d) W.-B. Liu, J.-B. Xia and S.-L. You, Top. Organomet. Chem., 2012, 38, 155; (e) P. Tosatti, A. Nelson and S. P. Marsden, Org. Biomol. Chem., 2012, 10, 3147.

10 Carreira and coworkers recently reported an iridiumcatalyzed reverse prenylation of 3-substituted indoles, affording the branched-selective indoline derivatives in excellent yields. The enantioselectivity was found to be $<20 \%$ ee, see: J. Ruchti and E. M. Carreira, J. Am. Chem. Soc., 2014, 136, 16756. For a recent Ir-catalyzed allylic alkylation of 3-substituted indoles affording linear-selective products, see ref. $5 \mathrm{f}$.

11 T. Kanayama, K. Yoshida, H. Miyabe and Y. Takemoto, Angew. Chem., Int. Ed., 2003, 42, 2054.

12 (a) W. Chen and J. F. Hartwig, J. Am. Chem. Soc., 2013, 135, 2068; (b) W. Chen and J. F. Hartwig, J. Am. Chem. Soc., 2014, 136, 377; (c) W. Chen, M. Chen and J. F. Hartwig, J. Am. Chem. Soc., 2014, 136, 15825. 
13 (a) W.-B. Liu, C. M. Reeves, S. C. Virgil and B. M. Stoltz, J. Am. Chem. Soc., 2013, 135, 10626; (b) W.-B. Liu, C. M. Reeves and B. M. Stoltz, J. Am. Chem. Soc., 2013, 135, 17298.

14 (a) S. Krautwald, D. Sarlah, M. A. Schafroth and E. M. Carreira, Science, 2013, 340, 1065; (b) S. Krautwald, M. A. Schafroth, D. Sarlah and E. M. Carreira, J. Am. Chem. Soc., 2014, 136, 3020.

15 (a) W.-B. Liu, H. He, L.-X. Dai and S.-L. You, Synthesis, 2009, 2076; (b) W.-B. Liu, C. Zheng, C.-X. Zhuo, L.-X. Dai and S.-L. You, J. Am. Chem. Soc., 2012, 134, 4812.

16 (a) Q.-F. Wu, H. He, W.-B. Liu and S.-L. You, J. Am. Chem. Soc., 2010, 132, 11418; (b) C.-X. Zhuo, W.-B. Liu, Q.-F. Wu and S.-L. You, Chem. Sci., 2012, 3, 205.

17 (a) J. F. Teichert and B. L. Feringa, Angew. Chem., Int. Ed., 2010, 49, 2486; (b) A. Alexakis and D. Polet, Org. Lett., 2004, 6, 3529.

18 (a) S. T. Madrahimov, D. Markovic and J. F. Hartwig, J. Am. Chem. Soc., 2009, 131, 7228; (b) J. F. Hartwig and L. M. Stanley, Acc. Chem. Res., 2010, 43, 1461; (c) S. Spiess, J. A. Raskatov, C. Gnamm, K. Brödner and G. Helmchen, Chem.-Eur. J., 2009, 15, 11087; (d) J. A. Raskatov, S. Spiess, C. Gnamm, K. Brödner, F. Rominger and G. Helmchen, Chem.-Eur. J., 2010, 16, 6601.
19 See the ESI $\dagger$ for details.

20 For the procedure of in situ generation of Ir-complex using $n$ $\mathrm{PrNH}_{2}$ : (a) T. Ohmura and J. F. Hartwig, J. Am. Chem. Soc., 2002, 124, 15164; (b) C. A. Kiener, C. Shu, C. Incarvito and J. F. Hartwig, J. Am. Chem. Soc., 2003, 125, 14272.

21 For the procedure of in situ generation of Ir-complex using dry TBD: (a) C. Welter, O. Koch, G. Lipowsky and G. Helmchen, Chem. Commun., 2004, 896; (b) C. Welter, A. Dahnz, B. Brunner, S. Streiff, P. Dübon and G. Helmchen, Org. Lett., 2005, 7, 1239; (c) C. Gnamm, C. M. Krauter, K. Brödner and G. Helmchen, Chem.-Eur. J., 2009, 15, 2050; (d) C. Gnamm, K. Brödner, C. M. Krauter and G. Helmchen, Chem.-Eur. J., 2009, 15, 10514.

22 In some cases, the allylic etherification of 2 or the subsequent allylic amination was observed, which was responsible for the low yield of 4 .

23 Synthesis of indoline with multiple stereocenters by Rh-, amine- or Cu-catalysis: (a) Y. Lian and H. M. L. Davies, J. Am. Chem. Soc., 2010, 132, 440; (b) Q. Cai, C. Zheng, J.-W. Zhang and S.-L. You, Angew. Chem., Int. Ed., 2011, 50, 8665; (c) H. Xiong, H. Xu, S. Liao, Z. Xie and Y. Tang, J. Am. Chem. Soc., 2013, 135, 7851. 